\title{
PROSTHETIC COMPLICATIONS IN IMMEDIATELY LOADED ALL-ON-FOUR MANDIBULAR PROSTHESIS USING TITANIUM WIRE REINFORCEMENT VERSUS NON REINFORCED TEMPORARY FRAMEWORK. A RANDOMIZED CLINICAL TRIAL
}

\author{
Ahmed Emad Fayyad*
}

\begin{abstract}
Objectives: The objective of this study was to evaluate the prosthetic complications resulting from the treatments performed with the All-on-Four concept either with splinted or un-splinted implants using the novel OT bridge system

Materials and Methods: This study was conducted on twelve completely edentulous patient aged from 60 to 70 years. An upper and lower removable complete denture were constructed for each eligible patient. CBCT scan was done for the patients to quantify bone volumes at the planned implant sites. All patients received 4 implants to support an "all-on-four" fixed mandibular prosthesis. The patients were randomly divided into two equal groups. The first group patients received an immediately loaded all-on-four mandibular prosthesis with un-splinted abutments. While the second group patients received an immediately loaded all on four mandibular prosthesis where the abutments were splinted together with titanium wire. Immediate loading was performed by converting the patients' existing denture into a fixed prosthesis by a picking up procedure at the day of implant placement. Prosthetic complications were evaluated for the temporary immediately loaded prosthesis in a 6-month period.
\end{abstract}

Results: In this study the overall prosthetic complications for those patients treated with splinted or un-splinted all on four technique was as follows: for Group I (un-splinted implants), total incidence of patients showed at least one Prosthetic complication were $12(100 \%)$ patients, while 4 (33.3\%) patients showed at least one Prosthetic complications in (Group II).

Conclusion: From this study it can be concluded that the All-on-four concept with immediate loading is a procedure that is viable and could be helpful in completely edentulous patients. However, it can predispose the patient to some prosthetic complications specially when the implants are unsplinted with titanium wires.

KEYWORDS: All on four; dental implants; splinted implants; edentulous mandible.

\footnotetext{
* Associate Professor, Prosthodontic Department, Cairo University
} 


\section{INTRODUCTION}

The rehabilitation of an atrophied edentulous mandible is a challenging situation for dental professionals. Implant-supported fixed restoration involving immediate loading improves the patients' quality of life and are becoming more popular and safer with high implant survival rate ${ }^{(1)}$.

The "all-on-four" treatment concept was developed in 1998 to maximize the use of the remaining jaw bone to place the jaw in immediate function and at the same time avoiding the costy regenerative procedures and additional patient morbidity, as well as the complications inherent to these procedures. The original protocol of the "allon-four" concept is the use of four implants in the anterior part of the completely edentulous mandible to support a provisional, fixed and immediately loaded prosthesis where the two anterior implants are placed axially parallel to each other while the two posterior implants are placed inclined distally in order to minimize the cantilever length and at the same time avoid the mental foramen by bringing the apex of the implant anterior to the foramen ${ }^{(1-6)}$

The rational of inclining the distal implants is advantageous and necessary as it increases the prosthetic support, reduces the length of the cantilever and allows the construction of up to 12 units prostheses, which increases the masticatory efficiency, thus reducing the need for bone grafts and also allows the installation of longer implants by avoiding areas of vital anatomic structures including mandibular canal and mental foramen ${ }^{(7,8)}$.

Although the All-on-four concept has many advantages, but it also has some limitations, such as the need to make a provisional acrylic prosthesis that has a higher incidence of fractures because the force applied to angled implants is magnified which might cause bone crest injuries up to five times larger than parallel implants. In addition, there are few long-term follow-up studies in the literature investigating the effects of this technique ${ }^{(5,9,10)}$.
In the last three decades, implantologists evaluated the implant success by implant survival rate, prosthesis stability, bone loss and absence of peri-implant soft tissue infection. Nowadays, new parameters are introduced to assess success in achieving a lifelike implant restoration. These parameters include natural looking peri implant soft tissue, esthetics and patient satisfaction. However, oseointegration remains the main parameter that evaluate success. It seems logic that the definition of success should be comprehensive to include these additional factors ${ }^{(11)}$.

When utilizing the immediate loading concept in implant prosthesis, we use either semirigid splinting with acrylic resin or rigid splinting by metal bar. The semi-rigid splinting doesn't offer adequate stress reduction on the bone around the implants but on the other hand this technique promotes better passivity to the implant- supported fixed prosthesis because of the absence of a metal support. This semi-rigid splinting has always been indicated for the healing period after implant placement (4-6 months), which is critical for implant survival. Degidi et al, 2012 realized the drawback of the semirigid splinting and so they recommended splinting of the abutments by titanium bar using intraoral welding ${ }^{(12)}$.

Several studies were concerned with studying the effect of both splinted and non-splinted implants in immediate loading. One of these studies evaluated the clinical and radiographic results of immediately loaded mandibular implants restored with fixed prostheses using either rigid or semirigid splinting systems. They concluded that both splinting techniques (rigid and semi-rigid) were satisfactory, and both splinting conditions can be successfully used for the restoration of edentulous mandibles ${ }^{(13)}$.

The OT bridge investigated in this research is a new restorative component that accommodate for different implant angulations up to 80 degrees and its configuration allow for a wire placement for splinting, accompanied by its low profile and width that provide better mechanical and biological outcomes. Only one multicentered study addressed 
the efficacy of the OT bridge, they reported preliminary data on survival and success rates of immediately loaded, screw-retained, implantsupported restorations delivered on lower arches using the novel OT equator and OT Bridge abutment prosthetic protocol ${ }^{(14)}$.

Therefore, this study aimed to evaluate the prosthetic complications resulting from the treatments performed with the All-on-Four concept either with splinted or un-splinted implants using the novel OT bridge system at Faculty of Dentistry, Cairo University.

\section{Methodology}

This study was conducted on twelve completely edentulous patient aged from 60 to 70 years. A full patient history was taken including personal information, medical history and dental history. It was then followed by an extra and intraoral examination to assess any problem that could contraindicate implant placement.

An upper and lower removable complete denture was constructed for each eligible patient. The lower denture was duplicated into clear acrylic resin which was modified with radiopaque markers at the proposed implant sites. This clear stent acted as the scan appliance for CBCT scan to quantify bone volumes at the planned implant sites.

\section{Surgical and immediate loading procedures}

On the day of implant placement, patients were instructed to rinse with $0.2 \%$ chlorhexidine mouthwash for 1 minute prior to the surgical procedure and to take two gm of amoxicillin one hour before the surgery (Patients allergic to penicillin were given Clindamycin $600 \mathrm{mg}$ ). All surgical procedures were implemented under local anaesthesia. After crestal incision and full-thickness flap elevation, the implant sites were prepared aided by the surgical template. 4 implants* were placed, 2 aligned in an axial orientation and 2 are distally aligned according to the all-on-four concept. The standard sequence of the osteotomy site preparation was followed to accommodate the selected implant size. Implants were ideally placed at bone level. The soft tissue thickness was assessed to decide the abutment height then the selected OT equator were screwed on each implant according to the manufacturer instruction, using a calibrated torque controller. After tightening of the OT equator** the flap was closed with vicryl 4.0 sutures. The titanium abutments were then screwed to the equator attachment with their prosthetic screw (Figure 1).

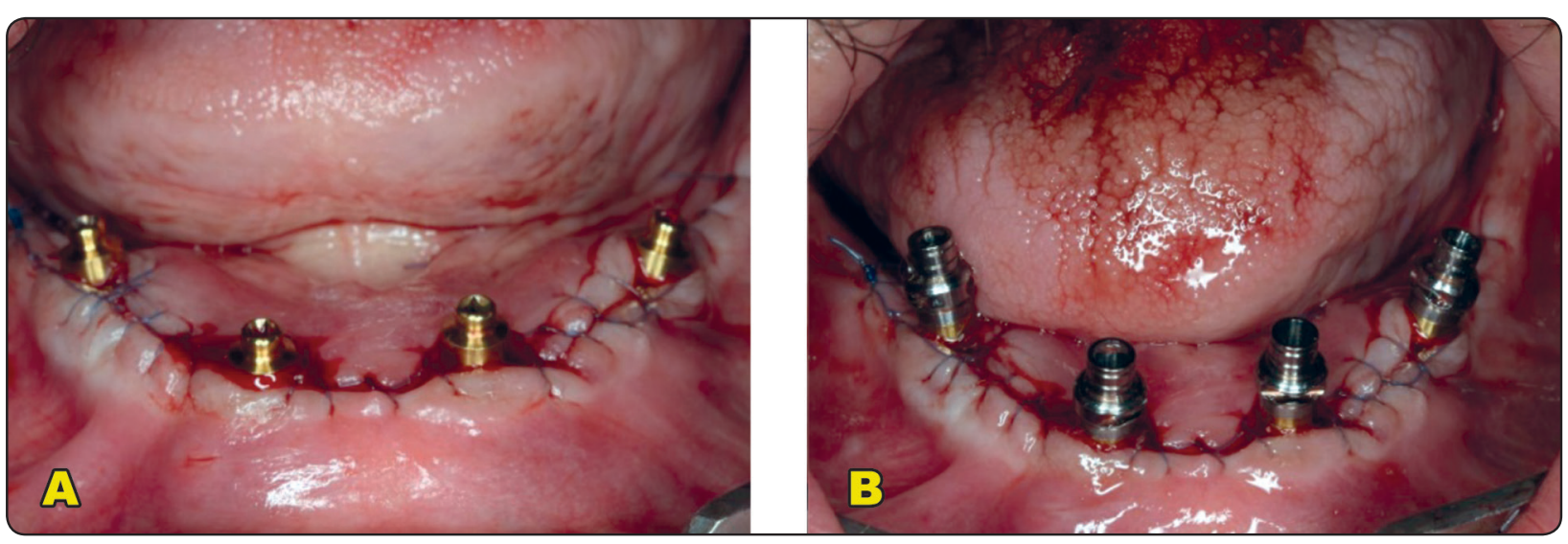

Fig. (1): a) The OT equator. b) The titanium abutment

\footnotetext{
* B \& B dental implant, San Pietro, Casale, Bologna, Italy.

** Rhein83, Bologna, Italy.
} 


\section{Patients Grouping:}

At this stage the selected patients were randomly divided into two equal groups

Group I Patients received an all-on-four mandibular fixed restoration supported by unsplinted OT bridge abutment.

Group II Patients received an all-on-four mandibular fixed restoration supported by splinted OT bridge abutment.

Pick up for the abutments was done at the day of surgery with the previously fabricated denture as follows:

\section{For group I (un-splinted group):}

A piece of rubber dam was fixed around the OT equator. The fitting surface of the denture was further relieved to create enough space surrounding the abutment assembly and to accommodate the self-curing denture base resin material*. A through and through tunnel was created to allow for escape of the excess resin to prevent excessive pressure on the soft tissue surrounding the implant (figure 2). The relief space was filled with self-cure resin in the dough stage then the denture was inserted in its place intraorally and the patient was guided to occlude at centric occlusion to secure the mandibular denture in its place till the resin hardens. The prosthesis was removed after the resin was cured, adjusted, finished and polished accordingly to assure a comfortable fit.

\section{For group II (splinted group)}

An impression was taken at the day of surgery using addition silicon material*** ${ }^{* *}$ to obtain a cast on which splinting of the abutments using the titanium wire could be easily done. The wires were then augmented by flowable composite to increase its rigidity (figure 3). After 24 hours the patient was recalled and the assembly was then fixed in the patient mouth for the pick-up procedures. The denture was prepared by making a trough over the abutments and the titanium wire. The same steps as in group I were then followed to complete the pickup procedure.

\section{Outcome}

Type and incidence of prosthetic complications for the immediately loaded prothesis for each group was evaluated in a six-month period. These complications included: loosening or fracture of the prosthetic screw, aesthetics, prosthesis mobility, fracture of the prosthesis and phonetics alteration.

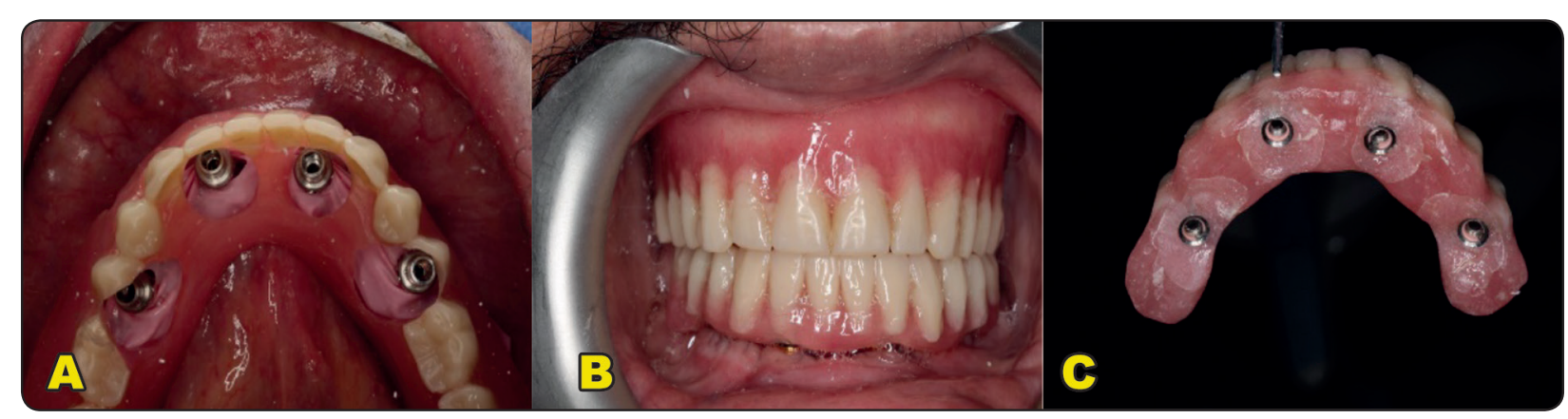

Fig. (2): a) the relived denture. b) patient occluding during pick-up procedure. c) finished denture after pick-up

\footnotetext{
* Qu-resin, Bredent, Weissenhorner, Senden, Germany.

** Panasil, Kettenback Dental Gmbh \& Co.
} 


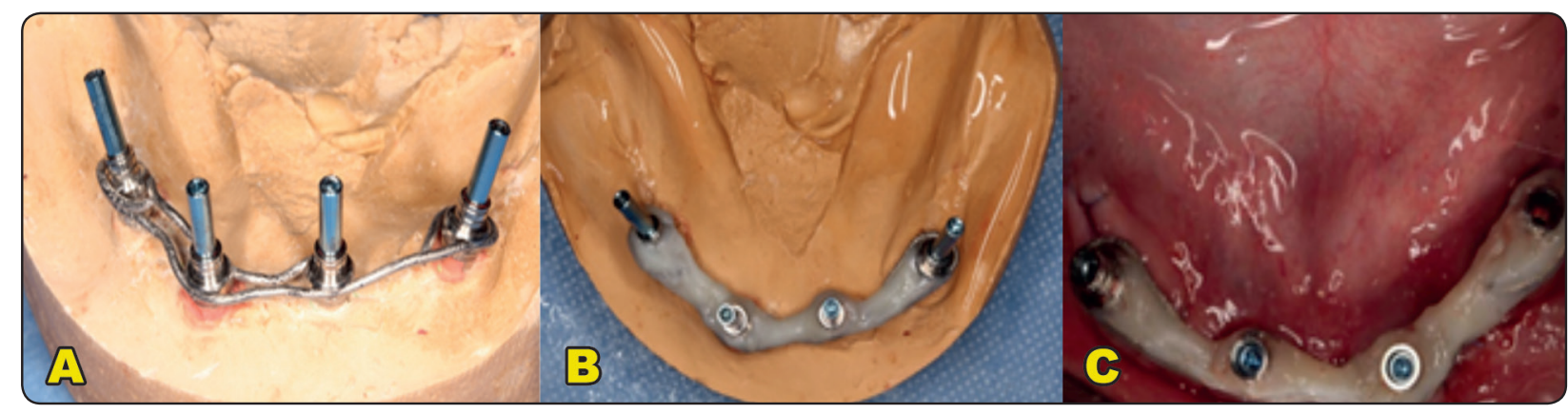

Fig. (3): a) abutments splinted with titanium wire. b) the wire augmented with flowable composite. c) the assembly intraorally.

\section{Results (figure 4)}

The mean and standard deviation values were calculated for the two groups under investigation. Datawere explored for normality using KolmogorovSmirnov and Shapiro-Wilk tests, data showed nonparametric distribution. Mann Whitney test was used to compare between two groups in non-related samples for qualitative data. The significance level was set at $\mathrm{P} \leq 0.05$. Statistical analysis was performed with IBM ${ }^{\circledR}$ SPSS ${ }^{\circledR}$ Statistics Version 20 for Windows.

The incidence of prosthetic complications was as follows (as shown in the table)

\section{Loosening of the prosthetic screw}

There was no statistically significant difference between (Group I) and (Group II) where ( $\mathrm{p}=0.148)$.

For (Group I), 2 (16.7\%) patients showed loosening of the prosthetic screw, while $0(0 \%)$ patients showed loosening of the prosthetic screw in (Group II).

\section{Fracture of the prosthetic screw}

There was no statistically significant difference between (Group I) and (Group II) where ( $\mathrm{p}=1)$.

For both groups, $0(0 \%)$ patients showed fracture of the prosthetic screw.

\section{Aesthetic}

There was no statistically significant difference between (Group I) and (Group II) where ( $\mathrm{p}=0.623$ ).
For (Group I), 3 (25\%) patients showed aesthetic problem, while $2(16.7 \%)$ patients showed aesthetic problem in (Group II).

\section{Prosthesis mobility}

There was no statistically significant difference between (Group I) and (Group II) where ( $\mathrm{p}=0.148$ ).

For (Group I), 2 (16.7\%) patients showed prosthesis mobility, while $0(0 \%)$ patients showed prosthesis mobility in (Group II).

\section{Prosthesis fracture}

There was no statistically significant difference between (Group I) and (Group II) where ( $\mathrm{p}=0.148$ ).

For (Group I), 2 (16.7\%) patients showed prosthesis fracture, while $0(0 \%)$ patients showed prosthesis fracture in (Group II).

\section{Phonetic alteration}

There was no statistically significant difference between (Group I) and (Group II) where ( $\mathrm{p}=0.623$ ).

For (Group I), 3 (25\%) patients showed phonetic alteration, while $2(16.7 \%)$ patients showed phonetic alteration in (Group II).

\section{Total Prosthetic complications}

There was a statistically significant difference between (Group I) and (Group II) where ( $\mathrm{p}=0.001)$.

For (Group I), total incidence of patients showed at least one Prosthetic complication were 12 (100\%) patients, while $4(33.3 \%)$ patients showed at least one Prosthetic complications in (Group II). 
A table showing the incidence of prosthetic complications in the two test groups

\begin{tabular}{|c|c|c|c|c|c|}
\hline Measurement & Prostheti & ations & n & $\%$ & p-value \\
\hline \multirow{5}{*}{$\begin{array}{l}\text { Loosening of the prosthetic } \\
\text { screw }\end{array}$} & \multirow{3}{*}{ Group I } & No & 10 & $83.3 \%$ & \multirow{5}{*}{ 0.148ns } \\
\hline & & & & & \\
\hline & & Yes & 2 & $16.7 \%$ & \\
\hline & \multirow[b]{2}{*}{ Group II } & No & 12 & $100 \%$ & \\
\hline & & Yes & 0 & $0 \%$ & \\
\hline \multirow{4}{*}{$\begin{array}{l}\text { Fracture of the prosthetic } \\
\text { screw }\end{array}$} & \multirow{2}{*}{ Group I } & No & 12 & $100 \%$ & \multirow{4}{*}{ 1ns } \\
\hline & & Yes & 0 & $0 \%$ & \\
\hline & \multirow{2}{*}{ Group II } & No & 12 & $100 \%$ & \\
\hline & & Yes & 0 & $0 \%$ & \\
\hline \multirow{5}{*}{ Aesthetic } & \multirow{3}{*}{ Group I } & No & 9 & $75 \%$ & \multirow{5}{*}{$0.623 n s$} \\
\hline & & & & & \\
\hline & & Yes & 3 & $25 \%$ & \\
\hline & \multirow[b]{2}{*}{ Group II } & No & 10 & $83.3 \%$ & \\
\hline & & Yes & 2 & $16.7 \%$ & \\
\hline \multirow{5}{*}{ Prosthesis mobility } & \multirow{2}{*}{ Group I } & No & 10 & $83.3 \%$ & \multirow{5}{*}{$0.148 n s$} \\
\hline & & Yes & 2 & $16.7 \%$ & \\
\hline & \multirow{3}{*}{ Group II } & & & & \\
\hline & & No & 12 & $100 \%$ & \\
\hline & & Yes & 0 & $0 \%$ & \\
\hline \multirow{5}{*}{ Prosthesis fracture } & \multirow{3}{*}{ Group I } & No & 10 & $83.3 \%$ & \multirow{5}{*}{$0.148 n s$} \\
\hline & & Yec & 2 & $1670 \%$ & \\
\hline & & & & & \\
\hline & \multirow{2}{*}{ Group II } & No & 12 & $100 \%$ & \\
\hline & & Yes & 0 & $0 \%$ & \\
\hline \multirow{5}{*}{ Phonetic alteration } & \multirow{2}{*}{ Group I } & No & 9 & $75 \%$ & \multirow{5}{*}{$0.623 n s$} \\
\hline & & Yes & 3 & $25 \%$ & \\
\hline & \multirow{3}{*}{ Group II } & & & & \\
\hline & & No & 10 & $83.3 \%$ & \\
\hline & & Yes & 2 & $16.7 \%$ & \\
\hline \multirow{5}{*}{$\begin{array}{l}\text { Total Prosthetic } \\
\text { complications }\end{array}$} & \multirow{2}{*}{ Group I } & No & 0 & $0 \%$ & \multirow{5}{*}{$0.001 *$} \\
\hline & & Yes & 12 & $100 \%$ & \\
\hline & \multirow{3}{*}{ Group II } & No & 8 & $66.7 \%$ & \\
\hline & & & & & \\
\hline & & Yes & 4 & $33.3 \%$ & \\
\hline
\end{tabular}




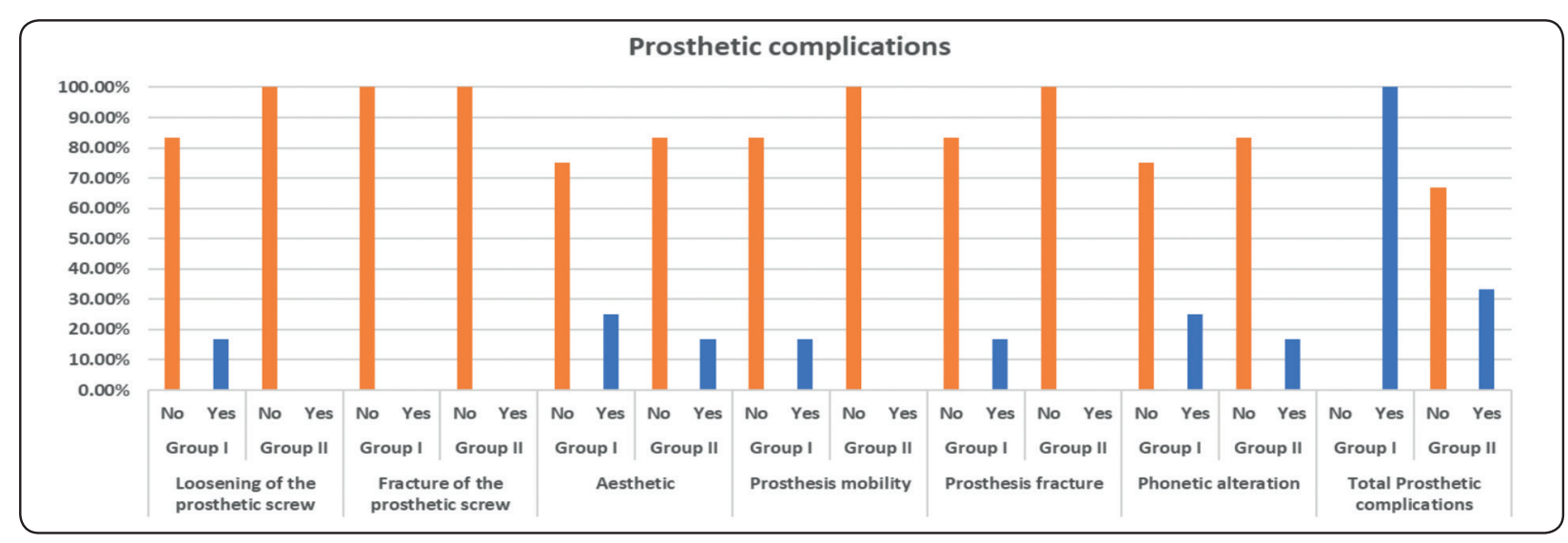

Fig. (4): Bar charts representing Prosthetic complications in different groups.

\section{DISCUSSION}

Nowadays, implantologists are looking for more conservative alternatives to treat completely edentulous patients who show anatomical constraints that requires extra surgical procedures like sinus lifting and bone augmentation before implant placement which may result in higher complications, extra surgical time and higher costs ${ }^{(10,15,16)}$.

The alternative and more conservative treatment for these cases is the All-on-Four ${ }^{\circledR}$ technique. In this technique two vertical implants are placed in the anterior region and two distally inclined implants in the posterior region. This technique also allows immediate loading of the implants, avoiding procedures that increase treatment costs as well as the complications inherent to the classical procedures ${ }^{(3,5)}$.

In this study the overall prosthetic complications for those patients treated with splinted or un-splinted all on four technique was as follows: for Group I (un-splinted implants), total incidence of patients showed at least one Prosthetic complication were 12 (100\%) patients, while 4 (33.3\%) patients showed at least one Prosthetic complications in (Group II).

The previously mentioned results of this study showed that the use of titanium wires in fabrication of immediately loaded implant supported prosthesis used in edentulous patients caused much lower overall prosthetic complications when compared to un-splinted one. This was in accordance to Collaert et al. 2008, who concluded that the use of glass fiber reinforced denture base caused higher prosthetic survival rate than the non-reinforced one ${ }^{(17)}$.

The results of this study might be due to the propagation of the stresses rapidly in a harmful manner in the non-reinforced group when forces during chewing is applied to the prosthesis causing fracture of the cantilever part or loosening of the prosthetic screw which was more evident in the un-splinted group of our study although was not statistically significant ${ }^{(18)}$.

Also the fracture of the distal cantilever in the non-reinforced group might be due to the emergence of the titanium abutment from the occlusal surface of the prosthesis causing inevitable thinning of the prosthesis at these areas and hens its weakening so fracture can occur easily at these areas which represent weak points of the prosthesis. This problem was not evident in the titanium reinforced group as the presence of the wire helped in keeping these areas rigid enough to resist fracture.

The phonetic complications in this study was evident after about 1 to 2 months from implant instalation and immediate loading procedure. This might be due to the space that occucred between the tissues and the prosthesis after healling and tisssue shrinkage. This change is inevitable but could be managed in the final prosthesis.. 


\section{CONCLUSIONS}

From this study it can be concluded that the Allon-four concept with immediate loading is a procedure that is viable and could be helpful in completely edentulous patients. However, it can predispose the patient to some prosthetic complications specially when the implants are un-splinted with titanium wires.

\section{REFERENCES}

1. Maló P, Rangert B, Nobre M. "All-on-Four" immediate function concept with Bränemark System Implants for completely edentulous mandibles: a retrospective clinical study. Clin Implant Dent Relat Res.2003;1:2-9.

2. Pomares C. A retrospective clinical study of edentulous patients rehabilitated according to the 'all on four or the 'all on six' immediate function concept. Eur J Oral Implantol. 2009; 2(1)55-60.

3. Bhering CL, Mesquita MF, Kemmoku DT, Noritomi PY, Consani RL, Barão VA. Comparison between All-on-Four and All-on-Six treatment concepts and framework material on stress distribution in atrophic maxilla: A prototyping guided 3D-FEA study. Mater Sci Eng. C Mater Biol Appl. 2016; 69:715-25.

4. Soto-Peñaloza D, Zaragozí-Alonso R, Peñarrocha-Diago MA, Peñarrocha-Diago M. The All-on-Four treatment concept: Systematic review. J Clin Exp Dent. 2017;9(3): 474-88.

5. Horita S, Sugiura T, Yamamoto K, Murakami K, Imai Y, Kirita T. Biomechanical analysis of immediately loaded implants according to the "All-on-Four" concept. J Prosthodont Res. 2017; 61:123-32.

6. Gherlone EF, Sannino G, Rapanelli A, Crespi R, Gastaldi G, Capparé P. Prefabricated Bar System for immediate loading in edentulous patients: A 5-year follow-up prospective longitudinal study. Biomed Res Int. 2018; 27:7352125.

7. Malo P, de Araújo Nobre M, Lopes A, Moss SM, Molina GJ. A longitudinal study of the survival of All-on-4 implants in the mandible with up to 10 years of follow-up. J Am Dent Assoc. 2011; 142:310-20.

8. Grandi T, Guazzi P, Samarani R, Grandi G. Immediate loading of four (All-on-4) post-extractive implants supporting mandibular cross-arch fixed prostheses: 18-month follow-up from a multicenter prospective cohort study. Eur J Oral Implantol. 2012; 5(3):277 -85.
9. Canay, S. Hersek N, Akpinar I, Asik Z. Comparison of stress distribution around vertical and angled implants with finite-element analysis. Quintessence Int. 1996; 27(9):591-8.

10. Maló P, Rangert B, Nobre M. All-on-4 immediate function concept with Bränemark System Implants for completely edentulous maxillae: a 1-year retrospective clinical study. Clin Implant Dent Relat Res. 2005;7:88-94.

11. Patzelt SB, Bahat O, Reynolds MA, Strub JR. The Allon-Four Treatment concept: A Systematic review. Clin Implant Dent Relat Res. 2014;16(6):836-55.

12. Degidi, M., Nardi, D., Sighinolfi, G. and Piattelli, A. (2012) 'Immediate rehabilitation of the edentulous mandible using Ankylos SynCone telescopic copings and intraoral welding: a pilot study', International Journal of Periodontics and Restorative Dentistry, 32(6), 687.

13. Lee, H. J., de Mattias Sartori, I. A., Alcântara, P. R., Vieira, R. A., Suzuki, D., Fontão, F. G. K. and Tiossi, R. 'Implant stability measurements of two immediate loading protocols for the edentulous mandible: rigid and semi-rigid splinting of the implants', Implant dentistry. 2012;21(6), 486-490.

14. Montanari, M., Scrascia, R., Cervino, G., Pasi, M., Ferrari, E., Xhanari, E., Koshovari, A. and Tallarico. 'A One-Year, Multicenter, Retrospective Evaluation of Narrow and Low-Profile Abutments Used to Rehabilitate Complete Edentulous Lower Arches: The OT Bridge Concept', Prosthesis. 2020;2(4), 352-361.

15. Pomares C. A retrospective clinical study of edentulous patients rehabilitated according to the 'all on four or the 'all on six' immediate function concept. Eur J Oral Implantol. 2009; 2(1)55-60.

16. Maló P, de Araújo Nobre M, Lopes A, Francischone C, Rigolizzo M. “All-on-4” immediate-function concept for completely edentulous maxillae: A clinical report on the medium (3 years) and long-term (5 years) out-comes. Clin Implant Dent Relat Res. 2012; 14: 139-50.

17. Collaert, B. and De Bruyn, H. Immediate functional loading of TiOblast dental implants in full arch edentulous maxilla: a 3-years prospective study. Clinical oral implants research. 2008; 19(12), 1254-1260.

18. Goldberg, J., Ronaghi, G., Phark, J.H., Jivraj, S. and Chee, W. Force-to-failure of a simulated implant supported complete fixed dental prosthesis reinforced with glass fiber. The journal of prosthetic dentistry. 2017; 118(2), 172-176. 